\title{
Severe hemolysis and methemoglobinemia following fava beans ingestion in glucose-6-phosphatase dehydrogenase deficiency_case report and literature review
}

\author{
Marijn Schuurman • Dick van Waardenburg • \\ Joost Da Costa $\cdot$ Hendrik Niemarkt • Piet Leroy
}

Received: 3 December 2008 / Accepted: 18 February 2009/Published online: 5 March 2009

(C) The Author(s) 2009. This article is published with open access at Springerlink.com

\begin{abstract}
Introduction Reduced concentrations of glucose-6-phospate dehydrogenase (G6PD) render erythrocytes susceptible to hemolysis under conditions of oxidative stress. In favism, the ingestion of fava beans induces an oxidative stress to erythrocytes, leading to acute hemolysis.

Discussion The simultaneous occurrence of methemoglobinemia has been reported only scarcely, despite the fact that both phenomena are the consequence of a common pathophysiologic mechanism. The presence of methemoglobinemia has important diagnostic and therapeutic consequences. We report a previously healthy boy who presented with combined severe hemolytic anemia and cyanosis due to methemoglobinemia, following the ingestion of fava beans. His condition was complicated by the development of transient acute renal failure. A G6PD-deficiency was diagnosed. We review the literature on the combination of acute hemolysis and methemoglobinemia in favism. Pathophysiologic, diagnostic, and therapeutic aspects of this disorder are discussed.
\end{abstract}

Keywords Child · Favism · Glucose-6-phospate dehydrogenase deficiency $\cdot$ Methemoglobinemia . Acute hemolysis

M. Schuurman $\cdot$ J. D. Costa $\cdot$ H. Niemarkt

Department of Pediatrics, Atrium Medical Centre Heerlen, Heerlen, The Netherlands

D. van Waardenburg $\cdot$ P. Leroy

Department of Pediatrics, Division of Pediatric Intensive Care, Maastricht University Medical Centre,

Maastricht, The Netherlands

P. Leroy $(\bowtie)$

Department of Pediatrics, University Hospital Maastricht, P.O. Box 5800, 6202 AZ Maastricht, The Netherlands

e-mail: P.Leroy@MUMC.nl

\begin{abstract}
Abbreviations
G6PD Glucose-6-phosphate dehydrogenase
\end{abstract}

\section{Introduction}

Glucose-6-phospate dehydrogenase (G6PD) is an intracellular enzyme that plays a key role in the protection of erythrocytes against oxidative stress. Reduced concentrations of G6PD render erythrocytes susceptible to hemolysis under oxidative conditions induced by oxidant drugs, infection, or ingestion of fava beans. The latter is known as favism [5].

Favism is characterized by acute hemolysis, hemoglobinuria, anemia, and jaundice. Headache, nausea, back pain, chills, and fever may be present [13]. Although elevated methemoglobin (metHb) levels have been observed during the hemolytic crisis of favic patients $[6,11]$, textbooks and recent review articles do not mention symptomatic methemoglobinemia as a clinical feature $[5$, 13]. However, the presence of methemoglobinemia has important diagnostic and therapeutic consequences.

We report a previously healthy child who presented with combined severe hemolytic anemia and cyanosis due to methemoglobinemia following the ingestion of fava beans. Moderate G6PD deficiency was diagnosed subsequently.

\section{Case report}

A previously healthy 1-year-old boy of Afghan origin presented to the emergency department with a 1-day history of malaise and irritability, without fever. His parents had noticed a bluish discoloration of the lips and dark-colored urine. The last 2 days, he had eaten freshly made red 
cabbage and fava beans. There was no history of jaundice and the boy was not on medication. Family history was negative for jaundice and blood diseases. His parents both tested negative for thalassemia.

Physical examination revealed an irritable child (weight $13 \mathrm{~kg}$, body length $84 \mathrm{~cm}$ ). He was pale and jaundiced and his lips were cyanotic. He had a body temperature of $38.3^{\circ} \mathrm{C}$, heart rate of $136 / \mathrm{min}$, respiratory rate of $40 / \mathrm{min}$, and an arterial blood pressure of 120/72 $\mathrm{mmHg}$. There was no respiratory distress. Auscultation of his heart and lungs revealed a systolic murmur and normal breathing sounds. There was no hepatosplenomegaly.

Oxygen saturation (SatO2), measured with a pulse oximeter (V24C, Agilent Technologies, Bäblingen, Germany), varied between $70 \%$ and $83 \%$, and did not increase after application of a non-rebreathing mask with $15 \mathrm{~L} / \mathrm{min}$ oxygen. Capillary blood gas results were $\mathrm{pH} 7.27, \mathrm{PCO}_{2} 4.1 \mathrm{kPa}$, bicarbonate $14 \mathrm{mmol} / \mathrm{L}$, and base excess -11.7 . The plasma hemoglobin level was $3.9 \mathrm{mmol} / \mathrm{L}$ (reference value, 6.0 $9.0 \mathrm{mmol} / \mathrm{L}$ ) and the plasma hematocrit was $0.20 \mathrm{~L} / \mathrm{L}$ (reference value, $0.34-0.42 \mathrm{~L} / \mathrm{L}$ ). Results of further laboratory investigations are listed in Table 1. Urinalysis showed the presence of both bilirubin and hemoglobin. A chest X-ray was normal. Methemoglobinemia was suspected because of the oxygen-resistant cyanosis without respiratory compromise or abnormalities on chest X-ray. Due to a technical error in the laboratory, the methemoglobin concentration was not determined on admission.

\section{Hospital course and outcome}

The diagnosis of severe acute hemolytic anemia was made. The patient was transfused with $200 \mathrm{~mL}$ erythrocytes, increasing the levels of hemoglobin and hematocrit to $5.3 \mathrm{mmol} / \mathrm{L}$ and $0.25 \mathrm{~L} / \mathrm{L}$, respectively. After transfusion $\mathrm{SatO} 2$ increased to $90 \%$. Arterial blood gas results were
pH 7.44, $\mathrm{P}_{\mathrm{a}} \mathrm{CO}_{2} 3.9 \mathrm{kPa}, \mathrm{P}_{\mathrm{a}} \mathrm{O}_{2} 50.2 \mathrm{kPa}$, and $\mathrm{HbO}_{2} 92 \%$. The methemoglobin level was $6.2 \%$ (reference value, $<1 \%$ ). Because methemoglobinemia caused no other symptoms besides cyanosis, it was not treated. The methemoglobin concentration decreased gradually, being $1.4 \%$ on day 4 .

The development of severe hemolytic anemia shortly after ingestion of fava beans raised strong suspicion on the presence of a G6PD deficiency. Laboratory testing revealed erythrocytic G6PD activity of $0.6 \mathrm{IU} / \mathrm{gram} \mathrm{Hb}$ (reference value, 3.8-5.9 IU/gram $\mathrm{Hb}$ in a child older than 3 months).

On the third day of admission, the patient developed acute renal failure. Maximum creatinine concentration was $232 \mu \mathrm{mol} / \mathrm{L}$ (reference value, $18-35 \mu \mathrm{mol} / \mathrm{L}$ ). Initially, the patient was treated with alkalinization and hyperhydration. Because of oliguria the hyperhydration was ceased and furosemide was given intravenously for 1 day. A normal diuresis returned and renal function started to improve. Subsequently, the patient's general and renal condition recovered completely.

\section{Discussion}

This case report illustrates that symptomatic methemoglobinemia may accompany a favic crisis in G6PD-deficient patients. However, recent textbooks and review articles on this topic do not mention this association $[5,13]$.

G6PD deficiency is an X-linked enzymatic defect. Antioxidant defense of erythrocytes is dependent on G6PD, which catalyzes the first reaction in the hexose monophosphate shunt, providing reducing power to the cell in the form of reduced glutathione (Fig. 1). G6PD-deficient erythrocytes exposed to oxidants become easily depleted of reduced glutathione, making them vulnerable to oxidative damage. Ultimately, further exposure to oxidative stress
Table 1 Blood chemical and enzyme values on admission

\begin{tabular}{lll}
\hline & & Reference values \\
\hline Reticulocytes $($ promille) & 53 & $5-15$ \\
Erythrocytes $\left(\times 10^{12} / \mathrm{L}\right)$ & 2.13 & $3.8-5.5$ \\
Total bilirubin $(\mu \mathrm{mol} / \mathrm{L})$ & 102.1 & $<17$ \\
Conjugated bilirubin $(\%)$ & $<10$ & $<10$ \\
Lactate dehydrogenase $(\mathrm{IU} / \mathrm{L})$ & 3,318 & $150-500$ \\
Aspartate aminotransferase $(\mathrm{IU} / \mathrm{L})$ & 152 & $15-55$ \\
Alanine aminotransferase $(\mathrm{IU} / \mathrm{L})$ & 41 & $5-45$ \\
Creatinine $(\mu \mathrm{mol} / \mathrm{L})$ & 40 & $27-62$ \\
Coombs test & Negative & \\
Electrolytes & Normal & \\
Coagulation tests & & $24-36$ \\
Activated partial thromboplastin time $(\mathrm{s})$ & 23.1 & $<1.15$ \\
Prothrombin time INR & 0.97 INR &
\end{tabular}


Fig. 1 G6PD and the hexose monophosphate shunt. Antioxidant defense of erythrocytes is dependent on G6PD, which catalyzes the first reaction in the pentose phosphate pathway. This reaction produces NADPH, which donates electrons to glutathione. Reduced glutathione is essential for the reduction of reactive oxygen species, thereby protecting hemoglobin and other erythrocytic proteins from oxidation

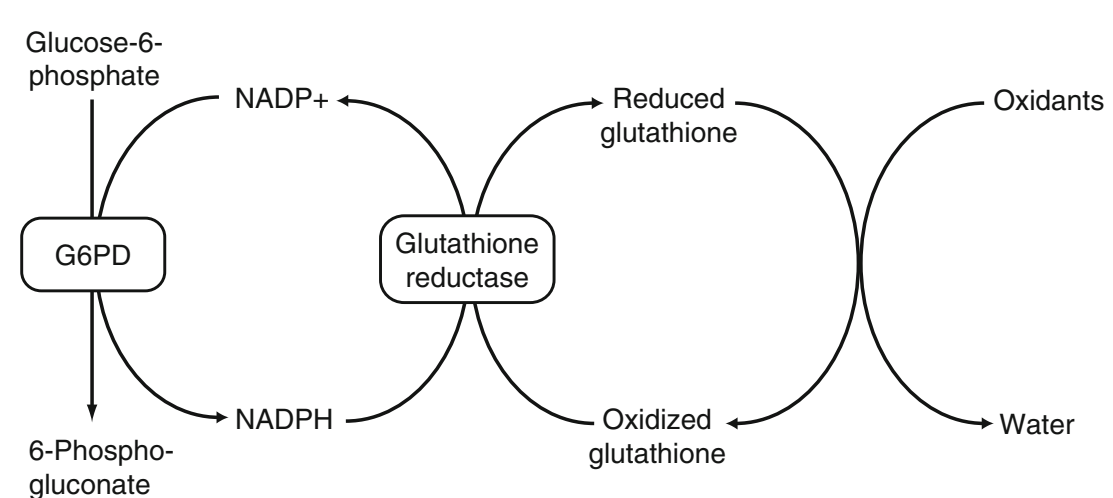

will lead to hemolysis. Common precipitants include infection, drug exposure, and, in susceptible subjects, ingestion of fava beans. Divicine, isouramil, and convicine are thought to be the toxic, oxidizing constitutes of fava beans [1].

Several oxidizing agents that induce hemolysis in G6PD-deficient patients may also induce methemoglobinemia $[10,19]$. Methemoglobin is a non-oxygen-binding form of hemoglobin that causes a bluish discoloration of the skin and mucous membranes, resembling cyanosis. High concentrations of metHb in the blood may cause tissue hypoxia. MetHb is produced when the oxygen carrying ferrous iron $\left(\mathrm{Fe}^{2+}\right)$ of the heme group is oxidized to the ferric ion $\left(\mathrm{Fe}^{3+}\right)$. This oxidative reaction occurs spontaneously in the presence of oxygen. However, in physiological conditions, metHb levels are maintained less than $1 \%$ of total hemoglobin by NADH-dependent cytochrome $b_{5}$-methemoglobin reductase. This enzyme accounts for $99 \%$ of daily metHb reduction [9]. If an exogenous oxidizing agent overwhelms this reducing system, metHb levels will increase. MetHb formation in favism is attributed to the excessive oxidative stress generated by divicine, which can not be reduced properly by the insufficient G6PD-dependent hexose monophosphate shunt [4].

A PubMed (US National Library of Medicine, Bethesda, MD, USA) search using the Medical Subject Headings (MeSH) "glucosephosphate dehydrogenase deficiency", "methemoglobinemia", and "hemolytic anemia" yielded several reports describing the combination of methemoglobinemia and hemolysis, precipitated by various agents, mostly oxidative drugs. In one report, dumplings were regarded as the precipitating agent [10]. Using the MeSH terms "favism" and "methemoglobinemia" a PubMed search yielded one study in which methemoglobinemia was reported to be present during favic crises. In seven favic patients, five children and two adults, methemoglobin levels over $5 \%$ were found to be present [6]. However, it was not reported whether symptomatic methemoglobinemia was found.
Diagnostic considerations

Measurement of SatO2 with pulse oximetry is not reliable in patients with methemoglobinemia. Pulse oximetry estimates $\mathrm{SatO} 2$ by emitting a red light (wavelength of $660 \mathrm{~nm}$ ) and an infrared light (wavelength of $940 \mathrm{~nm}$ ), which are respectively absorbed by desoxyhemoglobin and by oxyhemoglobin. MetHb absorbs equally at both wavelengths, which interferes with normal saturation measurement. When metHb level increases above $35 \%$, the $\mathrm{SatO} 2$ measured by pulse oximetry reaches a plateau of approximately $85 \%$ [9].

In our patient, the first metHb level measured was $6.2 \%$, which was after $200 \mathrm{~mL}$ erythrocyte transfusion. Before transfusion, metHb level must have been $9-10 \%$, taken into account the dilution effect of the transfusion. This metHb level does not explain measured $\mathrm{SatO} 2$ to be around $85 \%$. Probably, pulse oximeter function was impaired by other factors, including hyperbilirubinemia and severe anemia $[3,7]$.

In contrast to pulse oximetry, co-oximetry, as used for blood gas analysis in most hospital laboratories, is an accurate method to determine $\mathrm{SatO} 2$ and metHb levels. A co-oximeter measures light absorbance at four different wavelengths. A peak absorbance of light at $630 \mathrm{~nm}$ is used to characterize metHb [20].

Clinical signs of methemoglobinemia are dependent on metHb levels [20]. Cyanosis caused by methemoglobinemia becomes clinically apparent at a metHb level of $232 \mu \mathrm{mol} / \mathrm{L}$, which corresponds with $15 \%$ of total hemoglobin in healthy subjects [20]. However, patients with severe anemia may experience symptoms at much lower levels, because oxygen-carrying capacity is compromised both by true anemia and by functional anemia due to methemoglobinemia $[2,20]$.

\section{Therapeutic considerations}

The treatment of acute methemoglobinemia is dependent on the level of methemoglobinemia and the clinical presentation. In asymptomatic patients, the treatment action level is 
considered to be $30 \%$. Symptomatic patients (i.e. with clinical or laboratory signs of tissue hypoxia) and patients having concurrent problems that compromise oxygen delivery (e.g. anemia, circulatory failure), should be treated at levels between $10 \%$ and $30 \%$ [20].

The treatment of choice is methylene blue. The dose is 1 to $2 \mathrm{mg} / \mathrm{kg}(0.1-0.2 \mathrm{~mL} / \mathrm{kg}$ of the $1 \%$ solution) infused intravenously over 3 to $5 \mathrm{~min}$ [20]. However, in G6PDdeficient subjects, methylene blue should be used with caution. Methylene blue is an oxidant that is reduced by NADPH to its active metabolite, leukomethylene blue. Since NADPH is not sufficiently available in G6PDdeficient subjects, methylene blue cannot be reduced. Consequently, it will act as oxidant, precipitating or worsening hemolytic anemia $[12,15]$ and being ineffective in reducing methemoglobin levels in G6PD-deficient subjects $[8,17]$. If methemoglobinemia is life-threatening, methylene blue administration has still been suggested to be the first-line treatment in G6PD-deficient subjects, starting at a lower dose of 0.3 to $0.5 \mathrm{mg} / \mathrm{kg}$ and titrating upward to further reduce methemoglobinemia [14, 20]. Methylene blue may lower methemoglobin levels in these cases, because many G6PD-deficient subjects only have a partial enzyme deficiency. If the hemolysis worsens, methylene blue treatment must be abandoned and exchange transfusion should be considered [20]. In the presence of severe (hemolytic) anemia, transfusion of erythrocytes is indicated to treat both the true and functional anemia.

Our patient developed acute renal failure. Since he had not been treated with nephrotoxic drugs (e.g. aminoglycosides or NSAIDs) we believe that this was caused by a hemoglobinuria-induced acute tubular necrosis. Tissue hypoxia due to severe anemia, as suggested by the metabolic acidosis at presentation, may be an alternative explanation. The absence of other signs of organ failure makes this less likely. Acute renal failure is an important complication of severe hemolysis [21]. It has been reported to occur in severe hemolytic episodes in G6PD-deficient subjects [18]. In children, however, this complication occurs rarely. [11, 13] Hemolysis-induced renal failure may be prevented or treated with adequate fluid repletion and forced alkaline diuresis, in which the urine $\mathrm{pH}$ is raised to above 6.5 [21]. In oliguric patients, addition of furosemide or mannitol is indicated. In severe cases, renal replacement therapy may be necessary $[13,16]$.

Conflict of interest The writing of this case report has not been sponsored. Therefore, none of the authors has financial disclosures. Furthermore, none of the authors has any conflict of interest to be declared.

Open Access This article is distributed under the terms of the Creative Commons Attribution Noncommercial License which permits any noncommercial use, distribution, and reproduction in any medium, provided the original author(s) and source are credited.

\section{References}

1. Arese P, Mannuzzu L, Turrini F (1989) Pathophysiology of favism. Folia Haematol Int Mag Klin Morphol Blutforsch 116:745-752

2. Ash-Bernal R, Wise R, Wright SM (2004) Acquired methemoglobinemia: a retrospective series of 138 cases at 2 teaching hospitals. Medicine (Baltimore) 83:265-273

3. Beall SN, Moorthy SS (1989) Jaundice, oximetry, and spurious hemoglobin desaturation. Anesth Analg 68:806-807

4. Benatti U, Guida L, Grasso M et al (1985) Hexose monophosphate shunt-stimulated reduction of methemoglobin by divicine. Arch Biochem Biophys 242:549-556

5. Cappellini MD, Fiorelli G (2008) Glucose-6-phosphate dehydrogenase deficiency. Lancet 371:64-74

6. De Flora A, Benatti U, Guida L et al (1985) Favism: disordered erythrocyte calcium homeostasis. Blood 66:294-297

7. Fitzgerald RK, Johnson A (2001) Pulse oximetry in sickle cell anemia. Crit Care Med 29:1803-1806

8. Harvey JW, Keitt AS (1983) Studies of the efficacy and potential hazards of methylene blue therapy in aniline-induced methaemoglobinaemia. Br J Haematol 54:29-41

9. Haymond S, Cariappa R, Eby CS et al (2005) Laboratory assessment of oxygenation in methemoglobinemia. Clin Chem $51: 434-444$

10. Janssen WJ, Dhaliwal G, Collard HR et al (2004) Clinical problemsolving. Why "why” matters. N Engl J Med 351:2429-2434

11. Lau HK, Li CH, Lee AC (2006) Acute massive haemolysis in children with glucose-6-phosphate dehydrogenase deficiency. Hong Kong Med J 12:149-151

12. Liao YP, Hung DZ, Yang DY (2002) Hemolytic anemia after methylene blue therapy for aniline-induced methemoglobinemia. Vet Hum Toxicol 44:19-21

13. Luzzatto L (2003) Glucose-6-Phosphate Dehydrogenase Deficiency and Hemolytic Anemia. In: Nathan DG, Orkin SH (eds) Nathan and Oski's Hematology of Infancy and Childhood, 6th edn. W. B. Saunders, Philadelphia, p 721-742

14. Maddali MM, Fahr J (2005) Postoperative methemoglobinemia with associated G-6-P-D deficiency in infant cardiac surgery - enigmas in diagnosis and management. Paediatr Anaesth 15:334-337

15. Mullick P, Kumar A, Dayal M et al (2007) Aniline-induced methaemoglobinaemia in a glucose-6-phosphate dehydrogenase enzyme deficient patient. Anaesth Intensive Care 35:286-288

16. Nik-Akhtar B, Khakpour M, Rashed MA (1972) Recovery from acute renal failure from favism by means of dialysis. Trans $\mathrm{R}$ Soc Trop Med Hyg 66:801-802

17. Rosen PJ, Johnson C, McGehee WG et al (1971) Failure of methylene blue treatment in toxic methemoglobinemia. Association with glucose-6-phosphate dehydrogenase deficiency. Ann Intern Med 75:83-86

18. Sarkar S, Prakash D, Marwaha RK et al (1993) Acute intravascular haemolysis in glucose-6-phosphate dehydrogenase deficiency. Ann Trop Paediatr 13:391-394

19. Verma M, Aggarwal A (1977) Glucose-6 phosphate dehydrogenase deficiency with methemoglobinemia. Indian Pediatr 14:831-836

20. Wright RO, Lewander WJ, Woolf AD (1999) Methemoglobinemia: etiology, pharmacology, and clinical management. Ann Emerg Med 34:646-656

21. Zager RA (1996) Rhabdomyolysis and myohemoglobinuric acute renal failure. Kidney Int 49:314-326 